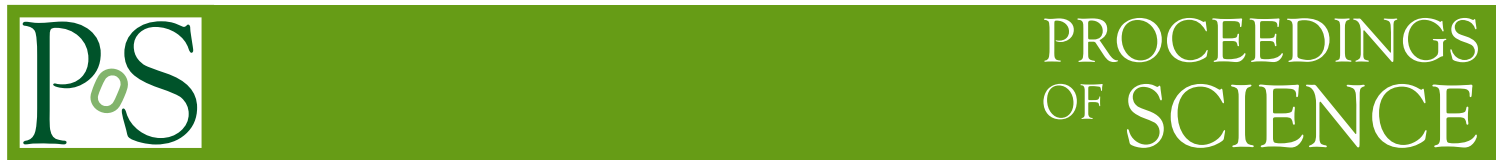

\title{
Expert prognosis of the future of astronomy
}

\section{Oleg Malkov*}

Institute of Astronomy, Moscow, Russia

E-mail: malkov@inasan.ru

Among other IYA2009 events in Russia, an expert prognosis of the future of astronomy was made. A list of 35 questions was compiled by Russian astronomy researchers and popularizers. Each question begins with "When will", e.g. "When will a man land on the Mars?" or "When will white holes be discovered?". The list was independently checked and corrected by scientific journalists. Russian astronomers then were asked to answer the questions, and the answers were collected, processed and averaged. For each event, the time and the probability were estimated. The questionnaire was also available to amateurs and enthusiasts of astronomy through the Internet. Their answers were processed separately and they were compared with the answers of professional astronomers. All results are presented in the paper.

Accelerating the Rate of Astronomical Discovery

August 11-14 2009

Rio de Janeiro, Brazil

${ }^{*}$ Speaker. 


\section{Russian astronomers opinion poll}

UN has proclaimed 2009 the International Year of Astronomy. It was an initiative by the International Astronomical Union (IAU) and UNESCO. The International Year of Astronomy (IYA2009) is a great event in scientific and cultural life of all nations. The IYA2009 activities are on several levels, however, the majority of IYA2009 events takes place locally and nationally.

One of the IYA2009 events in Russia was an expert prognosis of the future of astronomy. A list of 35 questions was compiled by Russian astronomy researchers and popularizers. Each question begins with "When will", e.g. "When will a man land on the Mars?" or "When will white holes be discovered?". The list was independently checked and corrected by three scientific journalists, and it was approved by National Committee of Russian Astronomers and by Scientific Council on Astronomy of the Russian Academy of Sciences.

Russian professional astronomers were asked to answer the questions. The questionnaire was also available to amateurs and enthusiasts of astronomy through the "IYA2009 in Russia" site www.astronomy2009.ru. Their answers were processed separately and they were compared with the answers of professional astronomers.

The first group of experts contains 119 professionals: researchers, post-graduate and graduate students. 90 of them are $\mathrm{PhD}$. This number can be compared with the number of Russian IAU members (350), which approximately corresponds to number of active Russian $\mathrm{PhD}$ astronomers. That means that our experts are about $1 / 4$ of number of leading Russian researchers in astronomy.

The other group of experts contains 55 amateurs and enthusiasts of astronomy.

\section{Answers processing}

The answers (year of event, e.g., 2050) were collected, processed and averaged. For each event, the "expected date" was estimated by quantil method: $16 \%$ of earliest and $16 \%$ of latest dates were discarded, other $68 \%$ were averaged. The resulting dates are given in columns $\mathbf{D}$ of Table 1.

The answers "Never" and "I do not know" were allowed as well. Beside date, the probability of each event was also estimated (columns $\mathbf{P}$ in Table 1. It depends on number of "Never"-like answers. We have also estimated a complexity of each question (columns $\mathbf{C}$ in Table 1: the less the number of "I do not know"-like answers, the simpler the question is.

Experts sometimes gave non-standard answers. Such "forbidden" answers were replaced by "allowable" ones according to the following rules:

- Interval (e.g., 2015-2020 or 2040ties) was replaced by a mean value (2018 or 2045).

- Upper limit (e.g., "by 2100") was replaced by "pessimistic" 2100.

- Lower limit (e.g., "after 2050") was replaced by "optimistic" 2050.

• "Soon", "Today" or "Just about" were replaced by 2009.

• "Senselessly" or "Needless" were replaced by "Never".

- "At any moment" was replaced by "I do not know" 
Answers like "Already" or "Already, in 2004" were considered as an evidence that a question is not quite correct. Such answers were not averaged and were processed separately; their fraction for each question is given in columns $\mathbf{A}$ of Table 1.

\section{Results}

Table 1: Results of the expertise

\begin{tabular}{|c|c|c|c|c|c|c|c|c|c|}
\hline \multirow[t]{2}{*}{ No } & \multirow[t]{2}{*}{ Event } & \multicolumn{4}{|c|}{ Professionals } & \multicolumn{4}{|c|}{ Amateurs } \\
\hline & & $\mathrm{D}$ & $\mathrm{P}$ & $\mathrm{A}$ & $\mathrm{C}$ & $\bar{D}$ & $\mathrm{P}$ & $\mathrm{A}$ & $\mathrm{C}$ \\
\hline 1 & $\begin{array}{l}\text { When will astronomy become } \\
\text { an obligatory subject in Russian } \\
\text { schools? }\end{array}$ & 2018 & 81 & 0 & 76 & 2017 & 89 & 0 & 85 \\
\hline 2 & $\begin{array}{l}\text { When will a sample of Martian soil } \\
\text { be transported to the Earth? }\end{array}$ & 2024 & 100 & 1 & 86 & 2023 & 100 & 2 & 96 \\
\hline 3 & $\begin{array}{l}\text { When will water on the Moon be } \\
\text { discovered? }\end{array}$ & 2025 & 61 & 8 & 73 & 2104 & 35 & 14 & 78 \\
\hline 4 & $\begin{array}{l}\text { When will a permanent astronomi- } \\
\text { cal observatory in the South Pole be } \\
\text { established? }\end{array}$ & 2026 & 90 & 9 & 89 & 2024 & 88 & 2 & 91 \\
\hline 5 & $\begin{array}{l}\text { When will the nature of gamma- } \\
\text { bursts be unraveled? }\end{array}$ & 2027 & 100 & 14 & 74 & 2053 & 97 & 3 & 69 \\
\hline 6 & $\begin{array}{l}\text { When will active study of Venus be } \\
\text { recommenced? }\end{array}$ & 2028 & 98 & 5 & 83 & 2037 & 94 & 0 & 87 \\
\hline 7 & $\begin{array}{l}\text { When will intermediate mass black } \\
\text { holes be discovered? }\end{array}$ & 2030 & 85 & 10 & 58 & 2041 & 80 & 0 & 64 \\
\hline 8 & $\begin{array}{l}\text { When will extremely massive (> } \\
200 \text { solar mass) stars be discovered? }\end{array}$ & 2032 & 52 & 8 & 62 & 2037 & 66 & 3 & 64 \\
\hline 9 & $\begin{array}{l}\text { When will gravitational waves be } \\
\text { registered? }\end{array}$ & 2032 & 96 & 3 & 68 & 2051 & 92 & 0 & 71 \\
\hline 10 & $\begin{array}{l}\text { When will a } 100 \text {-meter optical tele- } \\
\text { scope be constructed? }\end{array}$ & 2033 & 88 & 0 & 89 & 2029 & 78 & 0 & 89 \\
\hline 11 & $\begin{array}{l}\text { When will regular flights of private } \\
\text { spacecrafts begin? }\end{array}$ & 2034 & 92 & 1 & 87 & 2043 & 98 & 2 & 98 \\
\hline 12 & $\begin{array}{l}\text { When will satellites of satellites of } \\
\text { planets be discovered? }\end{array}$ & 2036 & 66 & 9 & 62 & 2192 & 51 & 0 & 64 \\
\hline 13 & $\begin{array}{l}\text { When will the nature of dark matter } \\
\text { be unraveled? }\end{array}$ & 2036 & 96 & 1 & 78 & 2056 & 93 & 0 & 75 \\
\hline 14 & $\begin{array}{l}\text { When will an exoplanet with all } \\
\text { four biomarkers (water, carbonic } \\
\text { acid, methane and oxygen) be dis- } \\
\text { covered? }\end{array}$ & 2036 & 97 & 3 & 73 & 2056 & 96 & 2 & 82 \\
\hline
\end{tabular}




\begin{tabular}{|c|c|c|c|c|c|c|c|c|c|}
\hline 15 & $\begin{array}{l}\text { When will solar sail be used for } \\
\text { space flights? }\end{array}$ & 2039 & 78 & 1 & 80 & 2061 & 72 & 0 & 91 \\
\hline 16 & When will a man land on the Mars? & 2039 & 96 & 0 & 88 & 2039 & 100 & 0 & 96 \\
\hline 17 & $\begin{array}{l}\text { When will existence of black holes } \\
\text { be unambiguously proved? }\end{array}$ & 2040 & 89 & 30 & 77 & 2043 & 88 & 14 & 78 \\
\hline 18 & $\begin{array}{l}\text { When will a permanent astronomi- } \\
\text { cal observatory on the Moon be es- } \\
\text { tablished? }\end{array}$ & 2046 & 96 & 0 & 88 & 2056 & 92 & 0 & 96 \\
\hline 19 & $\begin{array}{l}\text { When will the nature of dark energy } \\
\text { be unraveled? }\end{array}$ & 2046 & 97 & 4 & 73 & 2070 & 88 & 0 & 73 \\
\hline 20 & $\begin{array}{l}\text { When will nature of the Red Spot } \\
\text { on the Jupiter be unraveled? }\end{array}$ & 2048 & 99 & 14 & 74 & 2036 & 100 & 7 & 76 \\
\hline 21 & $\begin{array}{l}\text { When will a new Solar System body } \\
\text { larger than Mars be discovered? }\end{array}$ & 2052 & 20 & 1 & 72 & 2195 & 22 & 2 & 75 \\
\hline 22 & $\begin{array}{l}\text { When will tourist space flights be } \\
\text { widely available? }\end{array}$ & 2057 & 84 & 0 & 85 & 2055 & 98 & 0 & 96 \\
\hline 23 & $\begin{array}{l}\text { When will white holes be discov- } \\
\text { ered? }\end{array}$ & 2059 & 34 & 0 & 51 & 2093 & 31 & 0 & 58 \\
\hline 24 & $\begin{array}{l}\text { When will a manned flight beyond } \\
\text { the Martian orbit take place? }\end{array}$ & 2062 & 94 & 0 & 83 & 2061 & 100 & 0 & 91 \\
\hline 25 & $\begin{array}{l}\text { When will a sample of Saturn atmo- } \\
\text { sphere be obtained? }\end{array}$ & 2064 & 88 & 4 & 82 & 2060 & 93 & 2 & 84 \\
\hline 26 & $\begin{array}{l}\text { When will "worm holes" be discov- } \\
\text { ered? }\end{array}$ & 2065 & 58 & 0 & 64 & 2115 & 65 & 0 & 62 \\
\hline 27 & $\begin{array}{l}\text { When will the mankind begin to use } \\
\text { extraterrestrial sources of raw mate- } \\
\text { rials? }\end{array}$ & 2066 & 92 & 2 & 83 & 2065 & 98 & 8 & 93 \\
\hline 28 & $\begin{array}{l}\text { When will the mankind find assured } \\
\text { protection of the Earth from aster- } \\
\text { oid and comet impact hazards? }\end{array}$ & 2068 & 73 & 2 & 90 & 2171 & 66 & 0 & 80 \\
\hline 29 & $\begin{array}{l}\text { When will a fraction of solar en- } \\
\text { ergy in the mankind's industry ex- } \\
\text { ceed } 50 \% \text { ? }\end{array}$ & 2082 & 74 & 3 & 84 & 2090 & 78 & 0 & 91 \\
\hline 30 & $\begin{array}{l}\text { When will a convincing proof of an } \\
\text { extraterrestrial civilization's visit to } \\
\text { the Earth in the past be displayed? }\end{array}$ & 2088 & 26 & 0 & 75 & 2060 & 69 & 4 & 87 \\
\hline 31 & $\begin{array}{l}\text { When will public conveyances cir- } \\
\text { culate on the "Earth-Moon" route? }\end{array}$ & 2093 & 73 & 0 & 79 & 2129 & 78 & 0 & 93 \\
\hline 32 & $\begin{array}{l}\text { When will the Earth encounter with } \\
\text { an asteroid larger than the Tunguska } \\
\text { body? }\end{array}$ & 2096 & 80 & 1 & 68 & 2148 & 85 & 0 & 73 \\
\hline
\end{tabular}




\begin{tabular}{|c|l|l|l|l|l|l|l|l|l|}
\hline 33 & $\begin{array}{l}\text { When will Dyson Spheres be dis- } \\
\text { covered? }\end{array}$ & 2098 & 37 & 0 & 55 & 2105 & 45 & 0 & 56 \\
34 & $\begin{array}{l}\text { When will a radio signal of extrater- } \\
\text { restrial intelligence be detected? }\end{array}$ & 2108 & 51 & 1 & 66 & 2116 & 60 & 0 & 73 \\
$\begin{array}{l}\text { When will a contact with extrater- } \\
\text { restrials be established? }\end{array}$ & 2170 & 54 & 0 & 67 & 2265 & 70 & 0 & 73 \\
\hline
\end{tabular}

$\mathbf{D}$ and $\mathbf{P}$ are year and probability of event, respectively. $\mathbf{A}$ is a fraction of experts who consider the event already occurred. $\mathbf{C}$ indicates the question complexity, it is a fraction of experts who answered this question. $\mathbf{P}, \mathbf{A}$ and $\mathbf{C}$ are all in $\%$.

The results, provided by professional astronomers, are listed and discussed in this Section. Event probabilities are given in brackets.

Four of the listed events were recognized as unlikely: they have a probability less than $50 \%$. They are as follows:

- Discovery of a new Solar System body larger than Mars (20\%)

- Displaying of a convincing proof of an extraterrestrial civilization's visit to the Earth in the past $(26 \%)$

- Discovery of white holes (34\%)

- Discovery of Dyson Spheres (37\%)

We can expect the following events to happen within the next few years (year and uncertainty are indicated):

- 2018+12-6: astronomy becomes an obligatory subject in Russian schools - as it was in the USSR ages $(81 \%)$

- 2024+11-7: a sample of Martian soil is transported to the Earth (100\%). There are only two events in the list, which collected a $100 \%$ probability. The other is the nature of gammabursts: no expert has doubt it will be unraveled (see below).

- 2025+25-13: water on the Moon is discovered (61\%). Apparently, this event already happened. The expert prognosis was completed in March 2009, and first evidences of water on the Moon detected by Cassini [1], by Deep Impact [2] and by Chandrayaan-1 [3] were appeared in literature a half-a-year later.

- 2026+24-11: a permanent astronomical observatory in the South Pole is established (90\%)

- 2027+23-12: the nature of gamma-bursts is unraveled (100\%) [notably, $14 \%$ of experts answered "already unraveled"]

- 2028+22-13: active study of Venus is recommenced (98\%)

The following events will happen in the thirties and the fourties:

- 2030+42-15: intermediate mass black holes are discovered (85\%) 
- 2032+48-17: extremely massive (> 200 solar mass) stars are discovered (52\%) [note a relatively small probability of the event]

- 2032+28-17: gravitational waves are registered (96\%)

- 2033+17-13: a 100-meter optical telescope is constructed (88\%)

- 2034+66-17: regular flights of private spacecrafts begin (92\%)

- 2036+14-16: satellites of satellites of planets are discovered (66\%)

- 2036+64-21: nature of dark matter is unraveled (96\%)

- 2036+64-21: an exoplanet with all four biomarkers (water, carbonic acid, methane and oxygen) is discovered (97\%)

- 2039+32-19: solar sail is used for space flights (78\%)

- 2039+21-14: a man lands on the Mars (96\%)

- 2040+60-25: existence of black holes is unambiguously proved (89\%) [record-breaking high $-30 \%$ of experts consider it to be already proved]

- 2046+39-21: a permanent astronomical observatory on the Moon is established (96\%)

- 2046+54-26: the nature of dark energy is unraveled (97\%)

- 2048+52-28: the nature of the Red Spot on the Jupiter is unraveled (99\%) [remarkably, $14 \%$ of experts said: "already unraveled"]

After some pause, in the sixties, the following events will happen:

- 2057+43-37: tourist space flights are widely available (84\%)

- 2062+38-27: a manned flight beyond the Martian orbit takes place (94\%)

- 2064+45-34: a sample of Saturn atmosphere is obtained (88\%)

- 2065+135-45: "worm holes" are discovered (58\%)

- 2066+34-31: the mankind begins to use extraterrestrial sources of raw materials (92\%)

- 2068+32-32: the mankind finds assured protection of the Earth from asteroid and comet impact hazards $(73 \%)$

At the end of the XXI century we can expect the following events to happen:

- 2082+118-52: a fraction of solar energy in the mankind's industry exceeds 50\% (74\%)

- 2093+107-43: public conveyances circulates on the "Earth-Moon" route (73\%) 
- 2096+213-66: the Earth is expected to encounter with an asteroid larger than the Tunguska body (80\%). Pleasantly, it will happen 30 years after the mankind protects the Earth from cosmic impact hazards (see above). However, according to amateurs' expectations (see Figure 1, left panel, points 28 and 32) these two events will happen in an opposite order...

The remaining two events in the list have very late dates, large uncertainties and rather small probabilities:

- 2108+209-83: a radio signal of extraterrestrial intelligence is detected (51\%)

- 2170+330-120: a contact with extraterrestrials is established (54\%)

All results of the expertise (professional and amateur) are presented in Table 1 and in Figure 1.

\section{Difficult and simple questions}

The answers "I do not know" were counted for each question to estimate its complexity. The most difficult questions were the following (fraction of experts who answered the question is given in brackets):

- When white holes will be discovered? (51\%)

- When a Dyson Sphere will be discovered? (55\%)

- When will we discover intermediate mass black holes? (58\%)

And the most simple questions were:

- When a 100-meter optical telescope will be constructed? (89\%)

- When a permanent astronomical observatory in the South Pole will be established? (89\%)

- When the mankind will find an assured protection of the Earth from asteroid and comet impact hazards ? (90\%)

It can be seen from these lists that to estimate an expected date for a discovery of hypothetical objects is more difficult than to answer a question on a new technology.

\section{Comments to questionnaire}

The experts were allowed to leave comments to all questionnaire or to particular questions. Most comments were skeptical, like "Very strange list of questions. A half of them are ambiguous", "2/3 of astronomy is not broached", "many questions are devoted to narrow particular problems", "solar activity problems are not touched", "the questionnaire is a game for theorists", "incorrect question", "what other proof do you need?". Altogether about $10 \%$ of experts express some kind of a scepticism.

Frankly speaking, we have met words of approval in comments as well: "Thank you. It is an interesting idea". Although sceptical comments quantitatively significantly exceed approving comments (just one!), we believe the expert prognosis of the future of astronomy was not a lost labour. 

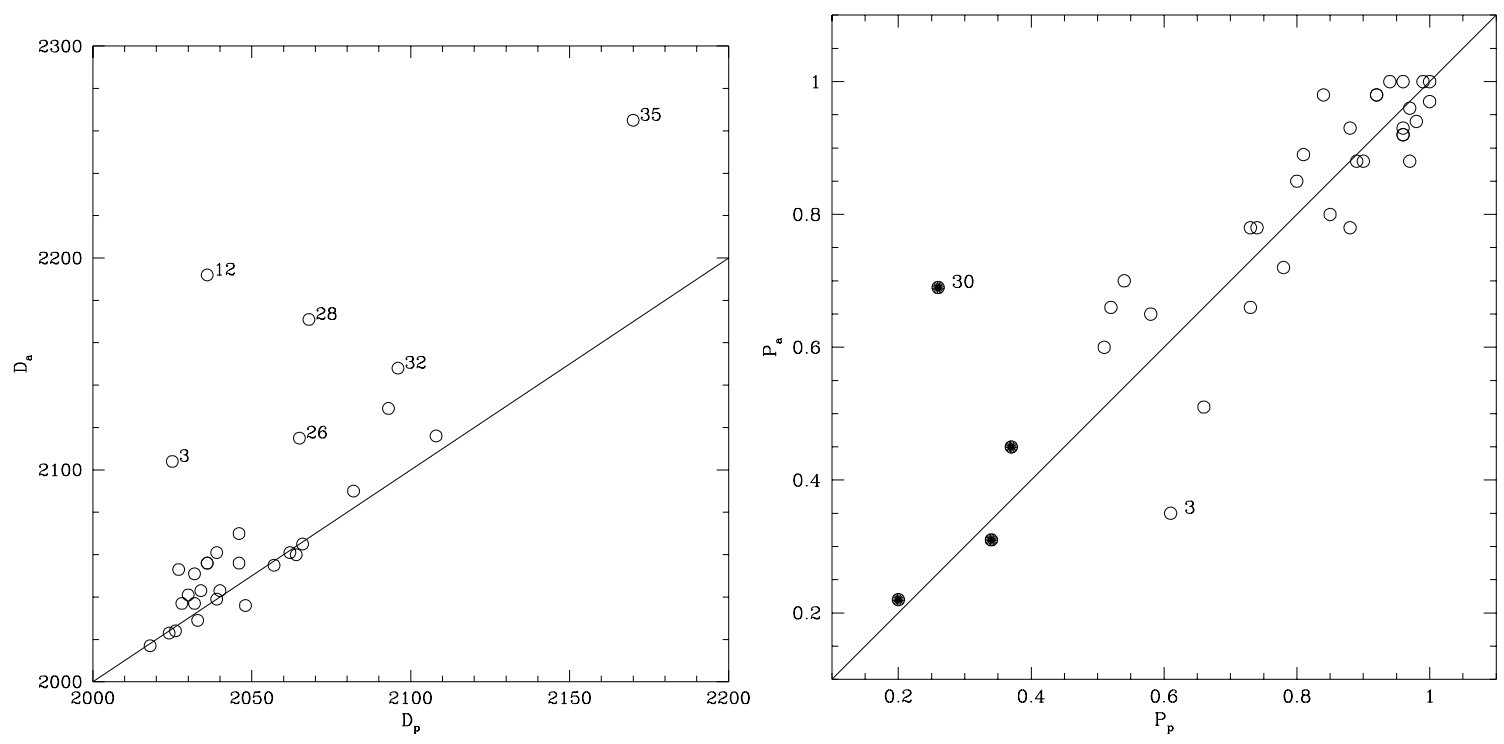

Figure 1: Professional vs. amateur estimations. Event numbers are taken from Table 1. Straight line indicates position of events of equal professional and amateur values. Left panel: event dates: $D_{p}$ vs. $D_{a}$. It can be seen that in general the amateurs are much more "pessimistic" than the professionals. Right panel: event probabilities: $P_{p}$ vs. $P_{a}$. One can see a surprisingly good agreement of estimations, with just a couple of exclusions. The most unlikely events (see beginning of Section 3) are not plotted in the left panel and indicated by filled circles in the right panel.

\section{Conclusions}

Such forecasts are always subjective. They rather indicate most interesting and strongly studied areas of knowledge. So it can be considered as a fun.

However, our experts are not any passers-by, but about a hundred of venerable professionals, who know problems and perspectives of present-day astronomy better than anybody else. So this forecast is the best that can be proposed today.

\section{Acknowledgments}

I am grateful to V.Surdin, B.Shustov, N.Grigorjeva, E.Kalashnikova and I.Yakutenko for the questionnaire compilation and E.Kilpio, D.Kovaleva and M.Prokhorov for useful discussions and for their help in collection and analysis of questions. I thank all the experts, professionals and amateurs, for the expertise.

\section{References}

[1] R. N. Clark 2009, Science 326, 562

[2] J. M. Sunshine et al. 2009, Science 326, 565

[3] C. M. Pieters et al. 2009, Science 326, 568 